\title{
Comparative study on the results of different tensile test methods of artificial frozen soil
}

\author{
Chang-yi Yu',2,3,4, Ming-yue $\mathrm{Lu}^{5}$ \\ ${ }^{1}$ CCCC-Tianjin Port Engineering Institute, Ltd., 300222 Tianjin, China \\ ${ }^{2}$ CCCC First Harbor Engineering Company, Ltd., 300461 Tianjin, China \\ ${ }^{3}$ Key Laboratory of Geotechnical Engineering, Ministry of Communications, 300222 Tianjin, China \\ ${ }^{4}$ Key Laboratory of Geotechnical Engineering of Tianjin, 300222Tianjin, China \\ ${ }^{5}$ Tianjin Survey and Design Institute For Water Transport Engineering, 300000 Tianjin, China
}

\begin{abstract}
Tensile strength of frozen soil is an important index for frozen soil engineering design. It is found that uniaxial tensile strength, three-point bending and four-point bending tensile strength values of frozen soil are inconsistent in the test. For this reason, the meso-level numerical method is adopted, assuming that the meso-level material parameters conform to Weibull distribution, and the damage model is adopted, and the macro-level material properties conform to linear elasticity assumption. Uniaxial tensile test, three-point bending tensile test and four-point bending tensile test are respectively simulated. The results show that the difference comes from the non-uniformity of materials. The results of this paper provide effective guidance for frozen soil strength design.
\end{abstract}

\section{Introduction}

Referring to "Influence of Loading Rate and Mode on Bending Strength of Artificial Frozen Soil", in the process of artificial freezing, natural rock and soil changes into artificial frozen soil, and its physical and mechanical properties will change significantly. The mechanical parameters of frozen soil in tunnel freezing project are the basis for freezing wall design and tunnel excavation. Therefore, thermophysical and mechanical testing of artificial frozen soil is the premise and necessary condition for reasonable design and safe construction in the design process of artificial freezing method. At present, the main basis of artificial frozen soil fracture resistance research is MT/T593-2011 "Physical and Mechanical Properties Test of Artificial Frozen Soil".

Frozen soil is widely distributed in nature, and many researches have been carried out on it. Whether in natural frozen soil engineering or artificial frozen soil engineering, the strength index of frozen soil is always an important parameter. Especially when frozen soil is used as underground supporting structure, its tensile strength is an essential index. However, at present, there are many methods to test the tensile strength of frozen soil: direct stretching, Brazilian disc stretching, four-point bending and three-point bending. However, the test found that the bending tensile strength and direct tensile strength of frozen soil are different[1], mainly due to the following factors: (1) Test error; (2) Tensile modulus and compressive modulus are different; (3) Test the surface effect of the sample, that is, the material is layered and the surface layer covers the material with higher strength; (4) non-uniformity of materials; non-linear change of stress-strain;

Firstly, this paper introduces the principle and calculation process of RFPA in mesoscopic mechanics system. Then, uniaxial tension, three-point and four-point bending tension of frozen soil are simulated respectively. Finally, the difference of results of different test intensities is analyzed.

\section{Numerical calculation method}

From a microscopic point of view, frozen soil materials are non-uniform materials. The Weibull distribution and linear elastic finite element method can be used to solve the fracture problem of mesoscopic inhomogeneous materials [2]. Assuming that the material parameters of the element conform to Weibull probability distribution, its function form is as follows [3].

$$
\varphi(\mathrm{A})=\frac{\mathrm{m}}{\mathrm{A}_{\mathrm{c}}}\left(\frac{\mathrm{A}}{\mathrm{A}_{\mathrm{c}}}\right)^{\mathrm{m}-1} \exp \left[-\left(\frac{\mathrm{A}}{\mathrm{A}_{\mathrm{c}}}\right)^{\mathrm{m}}\right]
$$

Where A_c is a scale parameter and $m$ is homogeneity. (5) The shape of the formula depends on the value of $\mathrm{m}$, and the material uniformity is represented by $\mathrm{m}$. When $\mathrm{m}$ increases, the material becomes more and more uniform. On the contrary, the more uneven the material.

In this paper, it is assumed that the mesoscopic material of frozen soil material is brittle material. During the loading process, the frozen soil material will be damaged, and visible cracks will be generated as the damage accumulates. According to Lemaitre's theory, there is the following formula: 


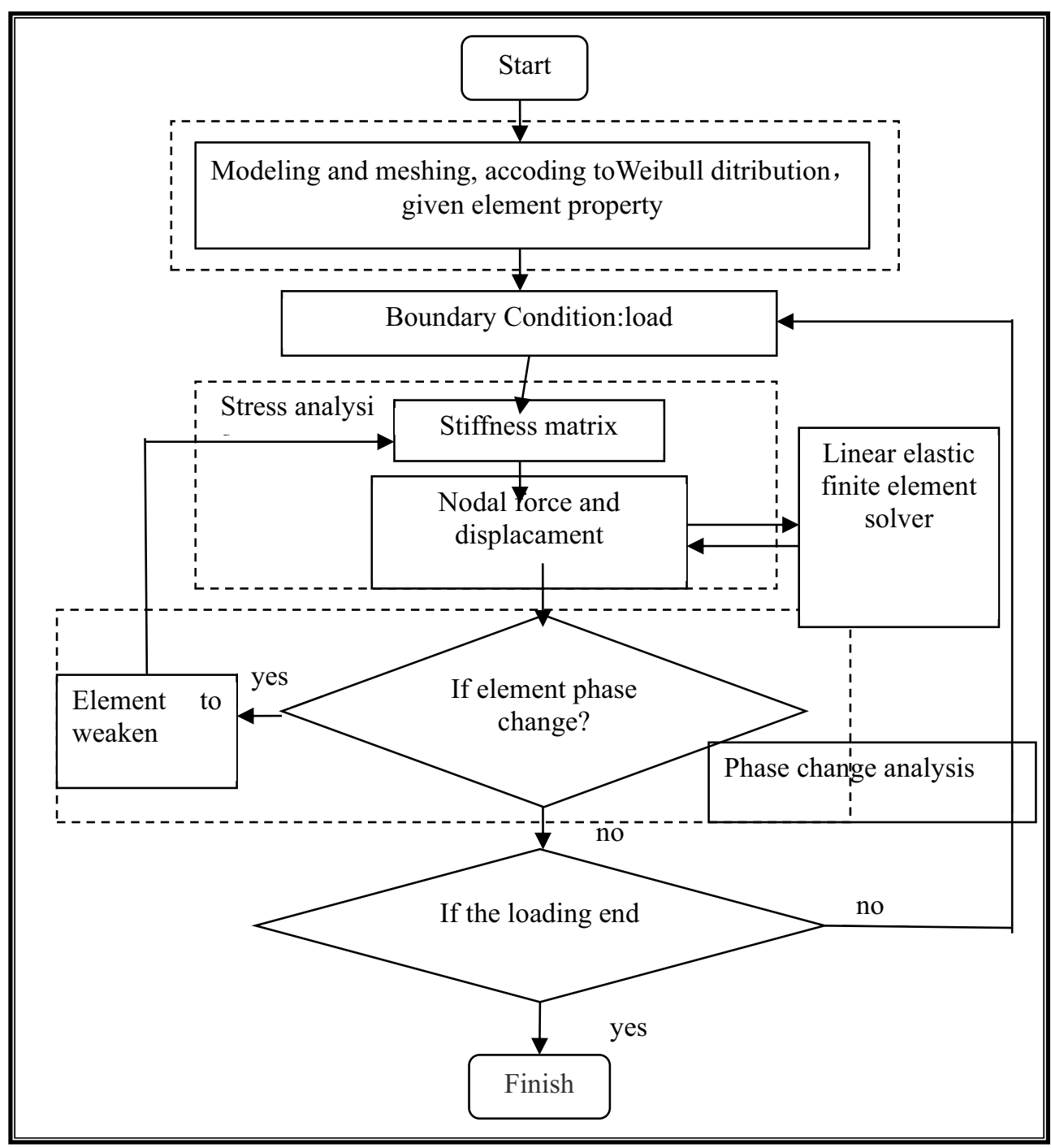

$$
\sigma=\mathrm{E}(1-\mathrm{D}) \varepsilon
$$

Figure1. Calculation flow

here $\sigma$ is the element stress, e is the elastic modulus, $\varepsilon$ is the strain, and $d$ is the damage value. In this paper, it is assumed that the mesoscopic material of frozen soil material is brittle material. During the loading process, the frozen soil material will be damaged, and visible cracks will be generated [4] as the damage accumulates. The RFPA calculation process is as follows [3].

\section{Models and Parameters}

At present, the stress-strain curve can be obtained in the laboratory through various instruments and equipment, but the test process is complicated and prone to errors. The numerical method can easily accomplish this task. In this test, a cylinder is used for uniaxial tensile test simulation. Generally, the dimension of the cylinder is 2:1 in height to diameter ratio, i.e. the height of the cylinder is $100 \mathrm{~mm}$ and the diameter is $50 \mathrm{~m}$.

When frozen soil is under tension, its macroscopic physical properties are elastic-plastic model and its microstructure conforms to Weibull distribution [5]. In general underground engineering, the design frozen soil temperature is -10 degrees Celsius [6]. According to this, we assume that the frozen soil parameters at -10 degrees Celsius are shown in the following table.

Table 1. Physical and Mechanical Parameters of Frozen Soil

\begin{tabular}{cccccc}
\hline $\mathrm{m}$ & $\begin{array}{c}\text { Density } \\
\left(\mathrm{kN} / \mathrm{m}^{3}\right)\end{array}$ & $\begin{array}{c}\text { Young's modulus } \\
\mathrm{kN} / \mathrm{m}^{2}\end{array}$ & $\begin{array}{c}\text { Poisson's } \\
\text { ratio }\end{array}$ & $\begin{array}{c}\text { Tensile strength } \\
(\mathrm{MPa})\end{array}$ & $\begin{array}{c}\text { Compressive strength } \\
(\mathrm{MPa})\end{array}$ \\
\hline 3 & 18.2 & 126.79 & 0.3 & 1.146 & 15.954 \\
\hline
\end{tabular}

According to the standard "test for physical and mechanical properties of artificial frozen soil MT_T 593.8-2011- test method for flexural strength of artificial frozen soil", the four-point bending test model is shown in figure 2. 


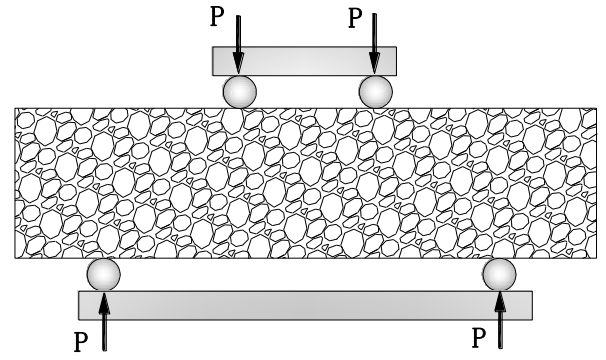

Figure 2. Schematic diagram of artificial frozen bending tensile test model

\section{Results analysis}

The experimental results are plotted as shown in the figure 3 .

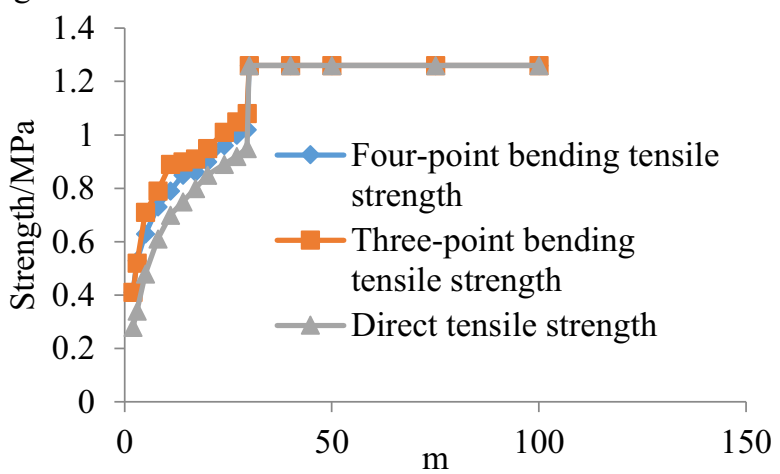

Figure 3. Relationship curve between $m$ value and tensile strength

Comparison of flexural properties of specimens under two loading modes The loading rate under four-point loading mode has no effect on flexural strength and the maximum relative deflection in mid-span when specimens are damaged, while the flexural strength and the maximum relative deflection in mid-span when specimens are damaged under three-point loading mode both increase linearly with the loading rate. The main reason for this difference is that the frozen soil beams under three-point and four-point loading have different mechanical conditions.

Three-point loading is an impure bending force. Under single-point concentrated loading, frozen soil beam has both bending and shearing force. Therefore, there are two types of damage to frozen soil beam, namely bending damage and shearing damage. The key is whether frozen soil beam reaches bending strength or shearing strength first. The four-point load is a pure bending force. Under symmetrical concentrated load, the frozen soil beam between symmetrical loads (i.e. the failure point) only has bending but not shearing force, so the failure of frozen soil beam can only be bending failure, i.e. bending failure.

The failure mode under three-point loading is shear failure, i.e. the test result is actually against the influence of shear strength instead of flexural strength, which conforms to the general rule that the strength increases with the increase of loading rate. The failure mode under four-point loading is bending failure, i.e. the frozen soil beam specimen is destroyed due to the deflection reaching the limit, which is consistent with the situation that only the flexural strength of frozen soil beam is studied.

Therefore, it is more reasonable to adopt four-point loading method to determine the flexural strength of frozen soil only from the study of its basic characteristics.

\section{Conclusion}

In the flexural strength tests of three-point and four-point loading modes, the relationship curve between load and deflection initially increases linearly, and then the deflection change rate increases. Under the two loading modes, the failure types show obvious brittle failure characteristics, and the effect of loading rate on the failure characteristics is negligible. Under the three-point loading mode, the flexural strength and the maximum mid-span relative deflection of silty clay at $-10^{\circ} \mathrm{C}$ both increase with the increase of loading rate and show a linear trend. The loading rate of the four-point loading mode has no influence on the flexural strength and the maximum relative deflection in the span when the specimen is damaged. Due to the different mechanical conditions of frozen soil beams under three-point loading and four-point loading, the effect of loading rate on the strength and the maximum relative deflection in midspan is different, which needs further research. It is more reasonable to adopt four-point loading method to determine the flexural strength of frozen soil only from the study of its basic characteristics.

\section{References}

1. D. A. FARRELL E L G A W E L. The effect of water content on axial strain in a loam soil under tension and compression [J]. Soil Science Society of America Journal, 1967, 31(4): 445-50.

2. L. G. THAM Y K C, C. A. TANG. Numerical Simulation of the Failure Process of Rocks [J]. Tamkang Journal of Science and Engineering, 2001, 4(4): 239-252.

3. Z.H. CHEN C A T, R.Q. HUANG. A double rock sample model for rockbursts [J]. International Journal of Rock Mechanics and Mining Sciences, 1997, 34(6): 991-1000.

4. TANG C A, YANG $\mathrm{W} T$, FU Y F, et al. A new approach to numerical method of modelling geological processes and rock engineering problems - continuum to discontinuum and linearity to nonlinearity [J]. Engineering Geology, 1998, 49(3-4): 207- 214.

5. TANG C A, KAISER P K. Numerical Simulation of Cumulative Damage and Seismic Energy Release During Brittle Rock Failure-Part I: Fundamentals [J] International Journal of Rock Mechanics and Mining Sciences, 1998, 35(2): 113- 121.

6. H. HAO C W, Y. ZHOU. Numerical Analysis of Blast-Induced Stress Waves in a Rock Mass with Anisotropic Continuum Damage Models Part 1 : Equivalent Material Property Approach [J]. Rock Mechanics and Rock Engineering, 2002, 35(2): 79-94. 